\title{
Desvendando o potencial de uma humanidade “outra” a través do pensamento indígena serrano
}

\author{
Patricia Lora León \\ Uniminuto, Bogotá, Colombia. \\ Email: patoloraleon@gmail.com
}

\begin{abstract}
Resumo: A partir dos artefatos comunicativos criados nas últimas décadas pelas organizações indígenas para a interlocução e o posicionamento do "pensamento próprio" diante dos representantes da sociedade nacional, a presente comunicação pretende mostrar como dos universos conceituais explicitados nos enunciados dos povos Kogui, Wiwa, Arhuaco e Kankuamo da Serra Nevada de Santa Marta na Colômbia, emerge uma compreensão "outra" sobre o sentido dos direitos humanos e sobre a noção de humanidade. Nesse contexto, os posicionamentos críticos indígenas apontam para a defesa da integralidadedas relações que perpassam o território e todas as formas de existência e, portanto, para o dever ser do cuidado da vida, alargando a compreensão sobre o sentido de ser humano na relação com o mundo.

Palavras chaves: pensamento ameríndio, etnopolítica, filosofia política, direitos humanos, humanidade.
\end{abstract}

\section{Revealing the potencial of"another" humanitythrough indigenous people's thought of the Sierra Nevada}

\begin{abstract}
Starting from communicative artifacts created in the last decades by the indigenous organizations of Sierra Nevada de Santa Marta (Colombia) in order to dialogue and express the "own way of thought" to representatives of the national society, this paper aims to shed light on how the conceptual universes explicited in the statements of Kogui, Wiwa, Arhuaco and Kankuamo people emerges an "another" understanding on the meaning of human rights and the notion of humanity. In this context, indigenous critical positions point to defend the entirety of relations that underlie the territory and all forms of existence and therefore to the imperative of taking care of life, expanding thus the meaning of being human in its relation to the world.
\end{abstract} rights, humanity.

Keywords: Amerindian thought, ethnopolitics, political philosophy, human

\section{Revelando el potencial de una humanidad “otra” a través del pensamento indígena serrano}

Resumen: A partir de los artefactos comunicativos creados en las últimas décadas por las organizaciones indígenas para la interlocución y el posicionamiento del "pensamiento propio" ante los representantes de la sociedad nacional, la presente comunicación pretende mostrar como a través de los universos conceptuales 
evidenciados en los enunciados de los pueblos Kogui, Wiwa, Arhuaco y Kankuamo de la Sierra Nevada de Santa Marta, emerge una comprensión "otra” sobre el sentido de los derechos humanos y sobre la noción de humanidad. En este contexto, los posicionamientos críticos indígenas se dirigen a la defensa de la integralidad de las relaciones que atraviesan el territorio y todas las formas de existencia, y por lo tanto, para el deber ser del cuidado de la vida, ampliando de esta manera la comprensión sobre el sentido de ser humano en la relación con el mundo.

Palabras clave: pensamiento amerindio, etnopolítica, filosofía política, derechos humanos, humanidad.

\section{Introdução}

O que significa ser indígena da Serra Nevada de Santa Marta ${ }^{1}$ no contexto de um território ancestral em disputa, no meio de forças que não só criam fissuras, mas rupturas profundas nos territórios, nas comunidades, no pensamento, na cultura, na natureza, nas formas de ser e de se habitar o mundo dos seus habitantes originários? A palavra é a resposta indígena ao desafio de existir num território em disputa, tensionado pela violência do conflito armado e pelo modelo de desenvolvimento "civilizado" que cada vez mais vai na contramão da cosmovisão e cosmovivência indígenas ancoradas na defesa da integralidade das relações com todas as formas de vida².

A comunicação tanto dos aspectos cosmológicos que contornam suas concepções de vida, como às “causas do não diálogo” que negligenciaram sua participação no contexto das disputas ocorridas no seu território ancestral desde o período colonial até hoje ${ }^{3}$, têm sido a estratégia política observada na análise dos artefatos comunicativos produzidos pelos povos indígenas Kogui, Wiwa, Arhuaco e Kankuamonas última décadas $^{4}$ (Lora 2015). Através de ditos artefatos - declarações, documentos conceituais, documentos de trabalho, cartas “abertas”, atas, manifestos, publicações e comunicados de imprensa - elaborados na relação com os representantes da sociedade nacional, e mais especificamente com o governo colombiano e suas instituições, denuncie-se enfaticamente a “incompreensão" sobre o universo de sentidos e significados que configura seu mundo, ao mesmo tempo em que se faz visível para a sociedade majoritária sua perspectiva sobre a relação em e com o território ancestral.

Num desses artefatos, o documentoLei de Se, SeynZare, Shenbuta: saúde indígena na Serra Nevada de Santa Marta, da Organização GonawinduaTayrona, resume-se desde a perspectiva indígena o quanto a ofensiva territorial pela apropriação dos recursos do maciço serrano no final da década de 90 e no inicio do século XX, assim como as acirradas condições de violência e a influência cada vez maior de grupos armados no controle de diversos corredores estratégicos ao longo do território ancestral -incluindo as zonas das reservas de uso exclusivo das comunidades indígenas- vêm afetando sistematicamente a integridade cultural e a ordem social tradicional dos povos serranos: 
“La guerra que se libra en nuestro territorio ocasionó una crisis humanitaria que amenaza la integridad cultural y el orden social tradicional. Las tierras de nuestros ancestros fueron tomadas por los hermanos menores por la fuerza o por la violencia. Los sitios sagrados, fundamentales en nuestra cultura, son destruidos y saqueados. Los bosques caen derribados y las aguas de las partes bajas de contaminan. Sobre las madreviejas y desembocaduras de los ríos nacidos de nuestras lagunas, construyen industrias y puertos que los destruyen y contaminan, sin el menor respeto ni consideración por nuestros conocimientos, valores o creencias. Enfermedades desconocidas aparecen ahora en nuestras comunidades. Inicialmente fueron los europeos, hoy son el Estado y muchas instituciones de la sociedad colombiana quienes persisten en una ofensiva material y cultural por dominar la sociedad y los territorios indígenas, intentando cambiar nuestra forma de vida, nuestro pensamiento y nuestros valores” (Organización GonawinduaTayrona2009:14).

Mas a estratégia de comunicação indígena não se circunscreve apenas ao exercício de denuncia ante o Estado e a comunidade internacional de direitos humanos destas e outras violações decorrentes do conflito armado que atinge ao maciço serrano e a seus habitantes originários. Trata-se por sua vez de um exercício de reflexão interno no qual a violência guerrilheira e paramilitar, assim como as diversas mega-iniciativas de desenvolvimento regional $^{5}$, configuram o pano de fundo no qual os universos conceituais próprios vem à tona para se criar vasos comunicantes com a linguagem ocidental de direitos humanos e pautar tanto o reconhecimento ancestral dos territórios (e o processo de titulação das reservas, por consequência) quanto o respeito pela integridade física e cultural ameaçada no meio da disputa violenta pela propriedade e/ou domínio dos seus territórios e os recursos que eles possuem.

Neste sentido, não existe desde a perspectiva serrana uma compreensão fragmentada dos diversos aspectos que configuram o todo sistêmico da ordem universal, na qual os direitos humanos possam ser isolados da trama das relações de interdependência e mutua afetação entre todas as formas de vida. Não existe, tampouco, uma assimilação acrítica da gramática de direitos humanos, uma “visão indígena” dos direitos ocidentais que se reduz exclusivamente a operacionalizar essas categorias jurídicas e instrumentalizá-las no âmbito da relação com as instituições do Estado colombiano. Existe, sim, uma extensão dessas categorias, que ao serem ressignificadas desde um universo de sentidos próprio, dialogam numa perspectiva crítica com a nossa concepção ocidental de direitos.

Assim os direitos, do ponto de vista serrano, foram incorporados como parte de sua visão integral do mundo, sendo ao mesmo tempo um instrumento necessário na interlocução institucional e no processo indispensável de transformação das relações assimétricas com a sociedade envolvente, e uma extensão conceitual do seu sentido da integralidade, uma categoria útil no processo de tradução para os “irmãos mais novos”ou 
não indígenas ${ }^{6}$ sobre o sentido da integralidade que perpassa os vínculos entre o material e espiritual, determinantes na relação indígena com todas as formas de existência. Desta forma, o território torna-se o "direito primigênio" sem o qual não é possível usufruir o que a natureza oferece, na fonte fundamental dos direitos “semeados” nos diferentes pontos da geografia sagrada, cenário dessa integralidade que possibilita a reprodução da vida.

"El territorio no es solamente un espacio definido como lugar, es decir, no es tan solo una magnitud en la que están contenidos los cuerpos, no es un afuera y por supuesto tampoco es una frontera entendida como una línea legal de la manera en que se entiende en la sociedad mayoritaria. El territorio es una escucha específica de nuestras culturas, de lo que dice la Madre Tierra. Por tal razón, los pueblos indígenas insistimos en el vínculo existente entre el sentido de la territorialidad y el sentido de pertenencia, pero éste no es sólo físico sino que es un vínculo entre lo material (físico) y lo espiritual. Ahora eso que llamamos espiritual podemos explicarlo como aquel entramado de relaciones vitales que nosotros los seres con existencia compartimos con la tierra. Ahora bien, la forma en cómo nuestro pueblo está en la tierra que nos vio nacer no tiene el aspecto de relación como cuando un vaso contiene agua (no es una relación de continente - contenido) sino que la relación que tenemos con nuestro territorio es similar a la relación del cómo el agua está implicada con el agua misma o la implicación que los pájaros tienen con el viento” (Confederación Indígena TayronaIbíd.: 52).

A integralidade dessas relações nas quais os sujeitos indígenas estão “implicados” como a agua com ela própria, como os pássaros com o vento, poderiam sinalizar-nos uma forma de compreensão "outra” sobre o sentido do "sujeito de direitos" estruturante da gramática dos direitos humanos desde uma perspectiva ocidental. Esse sujeito de direito “outro”, a meu ver, não seria propriamente uma subjetividade “outra” em si (os espíritos ancestrais, o território), mas o alargamento do sujeito individual na muldimensionalidade e pluriversalidade das relações com o território e com as diversas formas de existência (Damazio 2009) que configurariam a possibilidade de garantir a vida como a quinta-essência de qualquer direito possível.

Esse sujeito “outro”, portanto, seria o sujeito plural, polifônico e multiversal que surge na interligação com a diversidade espiritual e material da existência e que é preciso levar em consideração no intuito de fazer dos direitos fundamentais a práxis da relação indígena com o todo da ordem universal. Sujeito que diz respeito à integralidade do ser do território da Serra Nevada de Santa Marta e dos indígenas que são parte inerente desse vínculo entre o espiritual e o material, aspectos claramente relacionais não considerados pelos dispositivos jurídicos que visam proteger e garantir seus direitos, e que desde a perspectiva do pensamento serrano constituemse nos fundamentos de um ethos, de uma forma de compreender a relação 
do homem em e com o mundo, que preserva esse universo causal de relações pelas quais todas as formas de existência (subjetividades) participam da ordem e do equilíbrio do mundo.

Assim sendo, os indígenas serranos constituem-se nos sujeitos por trás dos direitos, partícipes fundamentais da integralidade dessas relações, nos agentes que possibilitam seus direitos existentes desde sempre, nos sujeitos que através dessa práxis de direitos fundamentais baseados no dever ser do cuidado possibilitam a garantia dos seus direitos ancestrais, e assim sendo, os direitos da humanidade, os direitos da vida como um todo.

\section{Dos sujeitos por trás dos direitos à humanidade do mundo}

Na perspectiva dos indígenas da Serra Nevada de Santa Marta homem e mundo atuam conjuntamente. A inter-relação das partes com o todo, explicitada na compreensão profunda da materialidade e da espiritualidade da geografia sagrada e na memória ancestral registrada no território, diz respeito ao atrelamento do individuo ao cosmos vinculado através da "universalidade" do espírito que interliga todas as formas de existência e transcende as fronteiras da espécie humana.

"Los indígenas de la Sierra nos consideramos como los hermanos mayores de la humanidad y nuestra principal función es cuidar el universo y todos los seres que lo conforman. Al hablar de seres, nos remitimos no sólo a lo que el no-indígena considera seres vivos animales, plantas, humanos-, sino también a todo lo que forma parte de la naturaleza - vientos, aguas, astros y demás fenómenos existentes-. En esa medida, la relación que los pueblos indígenas de la Sierra mantenemos con la naturaleza remite a una concepción de armonía y compenetración con ella considerando al hombre un miembro más; de ahí que en nuestras historias constantemente se habla de que los árboles o los animales también son gente y viceversa. Para lograr dicha relación, a la naturaleza la consideramos como la Madre Ancestral, como la madre espiritual de todo lo que existe” (Conchacala, Villafane1997: 90-91).

O papel que o humano cumpre na ordem cósmica para os indígenas da Serra Nevada, como evidenciado na dissertação do líder Kogui Arregocés Conchacala Zalabata, funda-se no “cuidado do universo” constituído por todos os seres por eles considerados ontologicamente como "irmãos de existência” (OrganizaciónGonawinduaTayrona 1993), configurando assim, como afirma Reichel-Dolmatoff (1975: 209), um modelo do dever ser da vida humana no qual é atribuído ao indivíduo uma grande responsabilidade pessoal pelo fundamento do universo e de cada um dos seus componentes. Portanto, a relação do homem com o mundo erige-se numa responsabilidade e no dever ser do cuidado, na qual o indivíduo faz-se responsável da "humanidade do mundo”, dos seus “irmãos de existência”, através da sua própria humanidade. 
Eis nessa chave que a violência sofrida pelas comunidades adquire uma dimensão maior à considerada pelas instituições e órgãos nacionais e internacionais de direitos humanos: encontra-se em jogo a relação com a multiplicidade de existências que habitam o mundo, a missão de cuidado da integralidade desses vínculos que no final das contas são as garantias da continuidade da vida e que fundam o sentido de ser indígena do maciço serrano.

Encontra-se em jogo, portanto, a possibilidade de continuar existindo segundo um ethos, segundo princípios culturais que diferem da perspectiva desenvolvimentista e de futuro a partir da qual a sociedade majoritária aborda a realidade da Serra Nevada de Santa Marta, seu território ancestral. Horizonte de futuro que mais uma vez não se reduz à sobrevivência física das comunidades, ao respeito dos direitos humanos no contexto da atual crise humanitária ou ao “desenvolvimento sustentável” proposto pelos “irmãos civilizados” no contexto da crescente exploração de "recursos naturais": trata-se de uma preocupação pela "humanidade do mundo”, por um sentido da responsabilidade indígena que consiste basicamente em continuar cumprindo a missão de "cuidado" de tudo que existe, segundo o estabelecido nos códigos originários.

Essa preocupação transparece em diversos artefatos comunicativos e nas narrativas das lideranças indígenas, junto com as demandas que reivindicam o reconhecimento das comunidades, das autoridades espirituais e políticas e das organizações como porta-vozes legítimos das questões que lhes dizem respeito. Assim, diante da destruição sistemática da vida em todas as suas manifestações, que atinge cada vez com mais força suas comunidades e autoridades e aos seus “irmãos de existência” (a água, as árvores, os rios, o petróleo, as pedras), consideram que nem a natureza nem a vida estão sendo considerados objetos de cuidado e sim alvo de destruição ou de apropriação para o benefício de poucos, apagando a ligação que vincula o humano com todas as formas de existência, para no final das contas constituírem cada um dos elementos com os quais interagem na relação com o mundo como fins em si mesmos, objetos de um propósito que não entende, como o faz a perspectiva indígena serrana, o dever do cuidado como o princípio fundante da vida e do equilíbrio universal.

O enunciado do cuidado com a humanidade, que claramente ganha destaque num cenário no qual as iniciativas de megaempreendimentos tais como barragens, portos, mineração e projetos turísticos radicalizam os processos de ocupação e profanação dos lugares sagrados, legitimam-se nos códigos éticos próprios através dos quais o sujeito indígena atrela-se como individuo ao cosmos, tornando-se responsável da continuidade da vida. Através desses códigos legados pelos pais e mães espirituais como afirma a liderança Arhuaca Marcelino Torres, exprime-se o "sentido de ser do indígena”, o qual "deve existir para continuar contribuindo com a preservação e a existência do ser humano e de todos os elementos que o rodeiam” 7 , tarefa que para AntonioSulit Malo, liderança Wiwa, precisa ser compreendida não simplesmente como uma questão vital para os quatro 
povos da Serra e sim como uma missão que deve se estender “à humanidade do mundo inteiro",

"No es que nosotros peleamos para nosotros no! sino es que es para la humanidad, eso lo tiene que entender el pueblo, el Estado, (...)no es para la vida humana nada más, sino es para la naturaleza, porque para nosotros esta piedra tiene vida, y eso es difícil para que lo entiendan, es que esto es una roca, pero para nosotros si tiene una vida porque mentalmente uno se comunica las autoridades principalmente los Mamos se comunican en ello" ${ }^{8}$.

No âmbito das lutas travadas contra as recentes iniciativas de exploração econômica, a expressão torna-se recorrente: "a gente não faz isto pela gente, a gente faz pela humanidade”, afirmam no intuito de reclamar a importância vital de dar continuidade às práticas culturais ancoradas no dever ser do cuidado. Mas como entender nesse contexto o enunciado serrano? Poderia ser interpretado como um posicionamento altruísta, como uma expressão de "amor pela humanidade"? O que significa, na perspectiva indígena, "fazer pela humanidade”?

O enunciado exprime, a meu ver, várias interpretações. Observo como os indígenas serranos procuram legitimar a própria existência do grupo e da cultura num contexto de violência e de usurpação do território ancestral por diferentes vias, posicionando-se politicamente no universo complexo de relações locais de poder que envolvem órgãos governamentais, organizações sociais, organismos internacionais, ONGs e atores armados, entre outros. Para outros (Ulloa 2004), nesse posicionamento é possível observar também a inserção dos indígenas serranos e suas organizações como "nativos ecológicos" entanto atores fundamentais na defesa do meio ambiente e na preservação dos "recursos naturais" no âmbito da atual "crise ecológica", legitimando seu lugar como "guardiões da biodiversidade".

Contudo, é importante notar que se bem a pauta ecológica do "irmão mais novo" cria condições políticas altamente favoráveis tanto às demandas indígenas pelo reconhecimento e respeito dos seus territórios como à configuração de uma discursividade capaz de colocar em diálogo a perspectiva indígena no âmbito global, todavia resulta indispensável evidenciar como isso acontece de fato no processo político serrano e como a perspectiva ocidental termina reduzindo e classificando desde sua compreensão do ecológico as práticas políticas, culturais, éticas e espirituais indígenas, em detrimento da especificidade e dos enunciados que contestam desde seu lugar de enunciação justamente a invisibilidade e marginalização de universos conceituais próprios sobre o sentido da natureza e do equilíbrio de todas as formas de vida.

Essa especificidade emerge claramente no documento Lineamentos dos povos indígenas da Serra Nevada para o manejo do território, da Organização Gonawindua Tayrona (1999), no qual os indígenas serranos apontam como o discurso e a prática do ecológico não conseguem exprimir 
suficientemente o enunciado nas suas narrativas e que diz respeito aos princípios que configuram o sentido de ser do indígena da Serra Nevada de Santa Marta:

“Para nosotros, el manejo ambiental tiene razón de ser en la medida de la íntima relación de todos los componentes de la vida y entre ellos está, por supuesto, el hombre; es precisamente en el conocimiento de las normas y en la puesta en práctica de todas ellas (...), las cuales son obligaciones del hombre, que está el sostenimiento a futuro de la naturaleza. Esto quiere decir que nadie es más importante que nadie en el desarrollo de la naturaleza, así como el tigre, la hormiga, el zaíno, los vientos o las quebradas, el hombre también forma parte integral de este sistema. Por eso antes los árboles o los animales fueron gente, porque todos formamos parte de un todo con derechos y obligaciones para que todo subsista. Esta es la ley y quienes la conocemos somos los indígenas de la Sierra, por eso ella sigue existiendo, porque ese conocimiento lo hemos mantenido y lo seguimos practicando con todos los problemas e dificultades que hemos mencionado” (Ibíd.:16)

No entanto, essa crítica ao "manejo ambiental” dos “irmãos civilizados” enunciada no documento da Organização GonawinduaTayrona corresponde a um posicionamento crítico que vem se contornando ao longo da década de 1990 não só com a discussão sobre o (re)ordenamento dos territórios indígenas, mas com a crítica das organizações indígenas serranas à formulação do Plano de Desenvolvimento Sustentável (PDS), talvez o projeto mais ambicioso do Estado colombiano por formular uma política pública de intervenção institucional regional em matéria de meio ambiente.

“Desde hace dos años el Estado asumió como política nacional un documento ampliamente conocido en la región llamada Plan de Desarrollo Sostenible de la Sierra Nevada de Santa Marta (PDS). Este documento fue elaborado a partir de diversos talleres donde se plantearon los problemas y las soluciones de los diversos sectores que habitan em la Sierra. Aunque en estos talleres los indígenas participamos, esta participación no fue representativa, ya que solo asistía una parte de las comunidades que no eran los representantes legales de nuestros intereses como pueblos indígenas. Por esta razón, cuando nuestras autoridades tradicionales conocieron el PDS, consideraron que el pensamiento tradicional no estaba plasmado en la dimensión que por razones históricas, políticas y sociales tenemos y dieron la orden a nuestras organizaciones de iniciar un proceso de consulta amplia que permitiera consignar los ajustes necesarios para así reivindicar el papel de los pueblos indígenas en el futuro de lo que la sociedad occidental llama ahora eco-región” (Consejo Territorial de Cabildos2007a: 1-2).

\section{A Declaração Conjunta das quatro organizações indígenas da Serra Nevada de Santa Marta para a interlocução com o Estado e a sociedade}


nacional adquire neste contexto uma importância capital. Como citado acima, a declaração surge precisamente como contestação ao Plano de Desenvolvimento Sustentável, evidenciando a necessidade de fortalecer os processos organizativos internos, a cultura própria e o papel das organizações indígenas enquanto interlocutoras dos povos serranos nos aspectos que dizem respeito ao futuro do território ancestral; mas visibilizando, por sua vez, os aspectos negligenciados na formulação da mencionada política ambiental e que dizem respeito sobre a relação que o pensamento indígena estabelece entre os códigos originários e a missão serrana de cuidado vinculada não apenas com o futuro do território ancestral e dos seus habitantes originários, mas com o futuro da vida e da humanidade como um todo.

“Esto no es un problema de unos cuantos indígenas caprichosos, es un problema que involucra a toda la humanidad. Por qué decidimos esto. La Sierra Nevada es el corazón del mundo, aquí están los orígenes de todo cuanto existe, siguiendo la ley de Sé, espiritualmente nosotros continuamos revitalizando la vida, hacemos la práctica, hasta donde podemos, de comunicarnos con los Padres espirituales de todos y cada uno de los seres que conforman la vida. Lastimosamente muchos de los sitios necesarios para continuar nuestra misión se han perdido, o no tenemos acceso a ellos o por la concepción de desarrollo (cada vez más equivocada) del hermanito menor”. (Ibid.:15)

Surge, dessa maneira, a recusa dos indígenas serranos a serem invisibilizados e marginalizados dos processos de planejamento que comprometem o território ancestral, enquanto esse território fica reduzido às noções externas de macrorregião, eco-região, zona rural ou de desenvolvimento sustentável (Serje2008), tudo isso em detrimento da dimensão sagrada que compreende esse espaço como fundamental para a formação e a continuidade da vida. Nesse sentido, contesta-se o modelo de desenvolvimento em pauta que entende a Serra Nevada como fonte de recursos e objeto de planejamento, assim como a própria ideia de desenvolvimento sustentável defendida no PDS que considera a conservação dos ecossistemas como garante da continuidade cultural dos povos serranos (Ulloa 2004: 59) e não a cosmovisão e cosmovivência indígenas como elementos fundamentais no equilíbrio da ordem natural.

Marca-se ao longo do artefato comunicativo citado os universos conceituais que definem um ethos indígena, uma forma de relação do homem com a natureza (e não a expensas dela) que procura acordos de convivência e a “escuta” dos representantes das instituições do Estado colombiano sobre uma perspectiva de futuro “outra” capaz de incidir nessa visão desenvolvimentista que afeta o caráter sagrado do território, a continuidade cultural dos povos serranos e a existência da humanidade e da vida como um todo.

“Actualmente nuestro territorio está desmembrado en 14 municipios, tres departamentos, tres corporaciones autónomas, dos res- 
guardos, dos parques y un sinnúmero de entidades y ONGs que, cada cual con su proyecto y su perspectiva de desarrollo, inciden en nuestro territorio, confundiendo el accionar de nuestros Mama para aplicar los principios básicos. Desde siempre nuestros mayores han manifestado que la mejor ayuda es, precisamente, apoyar la misión que nos dejaron desde el principio: poder cumplir los principios de Serankwa y de Seynekun, principios que solamente nosotros sabemos cómo cumplir, ese es el mandato que se nos encomendó. Está demostrado y aceptado por el Estado, que los pueblos indígenas somos los mejores conocedores del territorio de la Sierra Nevada. Creemos que en los actuales momentos, esta aseveración no tiene discusión. Por eso, nuestro llamado a cualquier plan de desarrollo, es precisamente impulsar lo indígena y la visión indígena ambiental como los ejes fundamentales para hacer de la Sierra el territorio que todos deseamos: conservando y produciendo vida” (Consejo Territorial de Cabildos, 2007a: 16).

Portanto, o significado do enunciado indígena não se esgota exclusivamente, a meu ver, na procura de serem atores posicionados na areia política e ecológica. "Fazer pela humanidade”, explicita o sentido de ser indígena serrano, o ethos, a forma de ser humano que pauta sua relação em e com mundo e que traduz na prática os princípios originários de cuidado com a vida como imperativo categórico que tece a realidade do mundo. A Lei de Origem, segundo os Kogui, "não exclui nenhuma sociedade ou grupo humano”, por que ela não se circunscreve às práticas culturais particulares de um grupo humano, “está por cima da cosmovisão de cada povo, pois diz respeito aos princípios da vida sobre o universo e as forças que o governam” (Confederación Indígena Tayrona 2011:39)

A humanidade indígena pretende, nesta medida, pautar a continuidade da vida como elemento essencial de qualquer compreensão sobre a realidade do mundo, como um imperativo categórico universal que se infere da compreensão e da prática dos códigos originários da Lei de Sé, como enunciado na Declaração dos $\operatorname{Mamos}^{9}$ ao Mundo, em 2003:

"Para nosotros no existe una sola ley - sagrada, inmutable, preexistente, primitiva ysobreviviente a todos y a todo. Podría el mundo existir o dejar de existir, sin que esto alteraraen lo más mínimo la esencia de dicha ley, la cual constituye el pensamiento universal de lo nomanifiesto, único origen de la vida. Esta ley de origen halla expresión en el universo. Se daentonces una hermosa asociación entre ley y pensamiento, que, a compás con el entorno, setransforma en ley natural. Esta ley natural da origen a la creación de la materia y a suevolución, equilibrio, preservación y armonía. Ellos constituyen los objetivos fundamentales delmamo, su razón de ser. El hecho es, no obstante, que el hermanito menor viola el ordeninmutable de esta ley y lleva a la Madre Tierra (Séineken) y a todos los seres vertiginosos aldespeñadero” (citada por Ulloa 2004: 203) 
O manifesto das autoridades espirituais serranasreúne as vozes dos mamos e autoridades Kogui, Wiwa, Arhuaco e Kankuamo com o propósito de declarar ao mundo "sua lei,” e nesse caminho, formular uma mensagem de abrangência global através da qual à "humanidade do mundo” conheça e respeite esse imperativo categórico universal ancorado nos códigos da Lei de Origem, “razão de ser” dos mamos e dos indígenas serranos.

“Nuestra ley es la ley del agua, es la ley del sol, la ley del rayo. No admite reformas, no conocedecretos, no acepta constituciones ni políticas, porque nuestra ley que rige la vida permaneceen el tiempo. Para que la armonía vuelva a nuestras vidas, es necesario que la ley creada porlos hombres respete y acate la ley de origen, la ley natural, la ley de la vida, la suprema ley delos mamos” (ibíd.. 205).

Nos diferentes pontos da declaração condensa-se claramente um posicionamento ético que surge da compreensão da experiência da Lei de Origem, a qual se torna referência para explicar à humanidade que existe uma "lei do cuidado da vida"que eles reconhecem e assumem como elemento fundamental para "o equilíbrio total do nosso planeta e da humanidade inteira”, a qual se torna imprescindível no momento no qual "o irmão mais novo”, desconhecendo e violando os princípios dessa lei, "leva a todos os seres, vertiginosamente, para o precipício”.

Na crítica levantada no manifesto, as autoridades indígenas reiteram o enunciado em outros artefatos comunicativos e depoimentos: o ethos serrano funda-se no dever ser do cuidado da vida, e assim sendo, naspráticas de cada ser humano capazes de incidir positiva ou negativamente na continuidade de todas as formas de existência. O que eles manifestam "fazer pela humanidade”, na verdade trata-se de um fazer-com-o-mundo, na medida em que realizam os rituais necessários para “pagar” a cada um dos donos espirituais de tudo quanto existe para assim obter as “permissões” requeridas para a ação conjunta do homem com o mundo, como explicam claramente no documento Visão Ancestral Indígena para o Ordenamento Territorial,

“Entre las distintas funciones que tienen los sitios sagrados para el cumplimiento de las normas, están el mantener todas las especies animales y vegetales, mantener el agua, la lluvia, prevenir o curar enfermedades tanto de los humanos como de la naturaleza, otorgar el poder a cada una de las autoridades, para la enseñanza de la historia, para la permanencia de las diferentes manifestaciones de la cultura, para la solución de conflictos entre las personas. Cada vez que se va a ejecutar una actividad que incida sobre el territorio, por ejemplo, tumbas, preparación del terreno para las siembras, cosechas, cacería, construcción de viviendas, caminos o puentes, es requisito fundamental hacer rituales de pagamentos para pedir permiso a los dueños de cada una de estas actividades o de los seres que van a ser utilizados en ellas, para mitigar los desequilibrios e impedir sus consecuencias, que usualmente se concretan en enfermedades o con- 
flictos sobre las personas que hayan realizado la acción” (Consejo Territorial de Cabildos2007b: 6-7).

Assim sendo, o que os indígenas serranos dizem "fazer pela humanidade" e que nós, os não indígenas, não fazemos, segundo o exposto na Declaração à Humanidade (citada por Ulloa 2004), é agir segundo o principio de que "tudo o que existe tem um espirito que é sagrado e deve ser respeitado", e nessa sacralidade, é ontologicamente constitutivo da existência humana tornando o que está para além das fronteiras da espécie num objeto de cuidado e "irmão de existência", em contraposição do que o "irmão mais novo" faz quando "trafica com os elementos e órgãos da sua própria Mãe” (Ibid: 205).

Declarando sua lei, como pretendido ao longo do articulado do texto, os indígenas serranos evidenciam seu lugar como cuidadores da Serra Nevada de Santa Marta entanto fonte vital e primaria de toda energia, origem da vida e do equilíbrio espiritual de Séineken (a Mãe Terra), confirmando o papel essencial do mamo e das práticas xamanísticas na comunicação com os pais e mães espirituais eestendendo ao mesmo tempo um chamado à humanidade para agir, assim como o determina seu dever ancestral, segundo o "indeclinável propósito de defender a vida em todas as suas manifestações” (Op. Cit) e de reparar os danos causados à Mãe Universal.

\section{Á maneira de conclusão}

A visão sobre o conceito de humanidade dos povos indígenas da Serra Nevada de Santa Marta, enunciada nas diversas narrativas citadas, fala das particularidades de uma experiência contemporânea de ser humano na relação com o mundo. Explicitada desde um lugar de enunciação próprio, essa humanidade indígena contesta com sua existência a universalidade da condição humana que pretende definir, estabelecer e contornar o sentido do humano nos moldes da razão instrumental e da retórica e gramática jurídica dos denominados direitos humanos.

Essa humanidade, com sua existência e voz própria, nos permite afirmar que não existe uma humanidade universal e sim, humanidades "em plural" que desde sua experiência e visão do mundo informa-nos sobre formas distintas de se compreender a essência do humano e sobre os dispositivos próprios através dos quais o homem, segundo a cosmovisão em jogo, compreende seu lugar na configuração igualmente diversa da realidade compartilhada do mundo.

Existe, portanto, uma humanidade propriamente indígena, embora marginalizada e invisibilizada no meio das relações assimétricas com a sociedade majoritária e da violência física e simbólica contra suas comunidades e culturas. Essa humanidade alça sua voz no intuito de garantir a sobrevivência física e cultural das comunidades no âmbito do seu território ancestral, mas defende, e de maneira veemente como tenho observado nos 
diferentes artefatos comunicativos analisados, a possibilidade de agir eticamente segundo os princípios que contornam a relação do cuidado indígena com todas as formas de existência no universo.

Nessa direção podemos afirmar que existe também, por sua vez, uma humanidade "outra” por trás dos seus enunciados. Sustento essa afirmação apoiada nos artefatos comunicativos emitidos desse lugar de enunciação próprio, textos construídos e agenciados coletivamente na procura de traduzir os universos conceituais que dizem respeito ao sentido de ser indígena na relação com o mundo, reproduzidos pela tradição oral e costurados através dos conhecimentos permanentemente recriados na práxis desses princípios em todas as ordens da vida cotidiana e política das comunidades. Nesses textos explicitam-se, a meu ver, elementos filosóficos que desvelam seu projeto ontológico ancorado nos vínculos que a práxis indígena precisa estabelecer com a ordem do todo.

Essa persistência ontológica manifesta-se claramente no exercício político pelo qual os indígenas insistem, na relação com os representantes da sociedade majoritária, na necessidade vital de dar continuidade a esse vincular-se permanentemente com a diversidade material e espiritual que configura o (seu) mundo, isto é, na defesa da integralidade dessas relações todas que fazem possível o cumprimento do seu dever ser originário no cuidado da vida. 


\section{Notas}

${ }^{1}$ A Serra Nevada de Santa Marta, Reserva Mundial da Biosfera desde 1979, é o maciço montanhoso mais alto do mundo ao lado mar. Localizada ao norte da Colômbia e isolada da cordilheira de Los Andes pelos vales dos rios Cesar e Rancherias, a Serra, com uma superfície aproximada de $17.000 \mathrm{~km} 2$ e uma altura de 5.755 metros, tem sido considerada como paraíso natural desde o século XIX por exploradores e viajantes colombianos e europeus assombrados com as suas extraordinárias condições geográficas, a diversidade de climas e de espécies de fauna e flora tropicais. Para seus habitantes originários, os povos indígenas Kogui, Wiwa, Arhuaco e Kankuamo, a Serra é seu território ancestral e o cenário do pensamento cosmológico que os configura enquanto guardiõesda Lei de Origem e irmãos mais velhos da humanidade: para eles a Serra Nevada de Santa Marta é o Coração do Mundo.

${ }^{2} \mathrm{O}$ presente artigo monstra resultados da tese doutoral em Ciências Sociais: Estabelecer pontes ou delimitar fronteiras: Desvendado o potencial de uma humanidade "outra" a partir do pensamento dos indígenas da Serra Nevada de Santa Marta, Colômbia (2014) Universidade Estadual de Campinas (Brasil).

${ }^{3}$ Os Kogui, Wiwa, Arhuaco e Kankuamo têm uma experiência histórica compartilhada. Desde o processo colonizador nos séculos XVII e XVIII, seguido pelas tentativas de integração destas comunidades no projeto de nação no século XIX, até hoje, os grupos serranos têm sido vítimas de reiterados processos de ocupação e de colonização do seu território ancestral, tornando-se, por sua vez, noalvo de várias tentativas de colonização espiritual, de imposição de instituições alheias às suas práticas culturais, de ocupação e perda no acesso aos lugares sagrados, e, mais recentemente, da violência desencadeada pela bonança local da maconha nos anos 70 do século XX e da disputa acirrada das guerrilhas, dos grupos paramilitares e do negócio do narcotráfico pelo controle territorial da região.

${ }^{4} \mathrm{Na}$ minha tese doutoral foram mapeados 76 artefatos comunicativos produzidos entre 1968 e 2012, denominados pelos indígenas como "manifestações conjuntas de pensamento" ou simplesmente como "documentos", "textos”, "escritos" ou "posicionamentos", emitidos desde um lugar de enunciação coletivo, embora em alguns casos trate-se de um exercício intelectual individual ou de porta-vozes individuais manifestando um enunciado coletivo.

5 Segundo o relatório Cuandola Madre Tierrallora: crisis em derechos humanos y humanitária em La Sierra Nevada de Gonawindúa (Santa Marta) (Fundación Cultura Democrática 2009), os principais megaempreendimentos que impactam a situação de direitos humanos dos povos indígenas serranos são a barragem El Cercado, de 23.000 hectares, sobre o ríoRancherias (território Wiwa); a barragem multipropósito Los Besotes sobre o Rio Guatapurí (território Arhuaco e Kankuamo); o porto multipropósito Brisa, iniciativa privada localizada em Yukulwa, lugar sagrado para os quatro povos serranos; e o desenvolvimento do etnoturismo na região que impactaria, principalmente, os lugares sagrados localizados no território Kogui.

${ }^{6}$ Como afirma Arenas (2009) e explicitam os indígenas através de artefatos comunicativos próprios, os povos serranos consideram-se a si mesmos como os irmãos mais velhos da humanidade, como herdeiros de um território delimitado ancestralmente pelos princípios da Lei de Origem e por um universo de relações cosmológicas 
comuns que os configuram como guardiões da vida e desses códigos originários.

${ }^{7}$ Entrevista com Marcelino Torres, etnoeducadorArhuaco. Riohacha, estado de La Guajira, em outubro de 2006

${ }^{8}$ Entrevista AntonioSulit Malo, ex-cabildogovernador .Badillo, estado de Cesar, em outubro de 2006

${ }^{9}$ Os mamos - denominados também como mamas pelos Kogui - são as “cabeças visíveis” dos quatro povos indígenas da Serra Nevada de Santa Marta, nas quais “conjugam-se as dimensões espirituais e materiais do exercício do poder”. Embora sua imagem tradicional de isolamento, de "sabedoria acumulada por séculos" e revestidos de "uma áurea de sacerdotes e seres iluminados", os mamos cumprem igualmente funções decisivas no governo sobre as comunidades e sobre o território. (Resguardo Kogui-Malayo-Arhuaco 2005). 


\section{Bibliografía}

Arenas, José (2012), Entre a harmonia e o caos. Contribuições para uma releitura da etnologia na Sierra Nevada de Santa Marta(Colômbia). Tese (Mestrado em Antropologia). Departamento de Antropologia, Universidade de Brasília, Brasília.

Conchacal, Arregocés; Villafane, Danilo (1997), “Autonomía y cultura en los kaggaba, ika y wiwa de la Sierra Nevada de Santa Marta”. Del Olvido Surgimos para traer Nuevas Esperanzas. Compilación de ponencias del Primer Seminario Nacional sobre Jurisdicción Indígena y Autonomía territorial. Ministerio de Justicia y del Derecho, Bogotá.

Confederación Indígena Tayrona (2011), Propuestas para el Programa de Garantías de los derechos fundamentales de los pueblos indígenas de Colombia. Valledupar.

Consejo Territorial de Cabildos (2007a), Declaración conjunta de las organizaciones indígenas de la Sierra Nevada para la interlocución con el Estado y la Sociedad Nacional, Imagen Visual, Valledupar.

Ídem (2007b), Visión Ancestral Indígena para el Ordenamiento Territorial de la Sierra Nevada de Santa Marta. Litoflash, Santa Marta.

Damázio, Eloise da Silveira (2009), “Descolonialidade e interculturalidade epistemológica dos saberes político-jurídicos: uma análise a partir do pensamento descolonial”. Direitos Culturais, Fortaleza, v. 4, No. 6. Disponível em: http://srvapp2s.urisan.tche.br/seer/index.php/ direitosculturais/article/viewFile/24/18. Acessoem: setembro, 2014.

Defensoría del Pueblo (2003), Informe de la comisión de observación de la crisis Humanitaria en la Sierra Nevada de Santa Marta (relatório). Disponível em http://www.acnur.org/t3/uploads/media/ COI_244.pdf?view=1. Acceso em: julho de 2014.

Fajardo, Luis Alfonso; Gamboa, Juan Carlos (1998), Multiculturalismo y derechos humanos: una perspectiva desde el pueblo indígena wiwa de la Sierra Nevada de Santa Marta. ESAP, Bogotá.

Fundación Cultura Democrática (2009), Cuando la Madre Tierra llora: crisis en derechos humanos y humanitaria en la Sierra Nevada de Gonawindúa (Santa Marta), Fundación Cultura Democrática, Bogotá.

Fundación Pro-Sierra Nevada de Santa Marta (1995), Bases para un plan de desarrollo regional sostenible para la Sierra Nevada de Santa Marta: documento borrador para discusión. La Fundación, Santa Marta.

Lora, Patrícia (2014), Estabelecer pontes ou delimitar fronteiras? Desvendando o potencial de uma humanidade "outra” a partir do 
pensamento dos povos indígenas da Serra Nevada de Santa Marta, Colômbia. (Tese inédita de doutorado). Universidade Estadual de Campinas, Campinas.

Organización GonawinduaTayrona (2009), Lei de Se, SeynZare, Shenbuta. Salud Indígena en la Sierra Nevada de Santa Marta. Sirga Editores, Bogotá.

Ídem (1999), Lineamientos de los pueblos indígenas de la Sierra Nevada para el manejo del territorio (Documento de trabajo). Santa Marta.

Ídem (1993), Difusión y consulta del ordenamiento territorial.(Documento de trabajo)

Reichel - Dolmatoff, Gerardo (1975), “Templos kogi. introducción al simbolismo y a la astronomía del espacio sagrado”. Revista colombiana de antropología, Vol. 19, no. 4, p. 199- 245, Bogotá.

Resguardo Arhuaco (2006), Los derechos humanos y los derechos fundamentales de los pueblos indígenas de la Sierra Nevada de Santa Marta, Formatos Imagen \& Publicidad, Santa Marta.

Resguardo Kogui-Malayo-Arhuaco (2005), Mamalwa- Modelo ancestral de ordenamiento territorial indígena cuenca del río Santa Clara Sierra Nevada de Santa Marta. Santa Marta, Formatos Imagen \& Publicidad.

Serje, Margarita (2008), “La invención de la Sierra Nevada”. Antípoda, No. 7, p. 197-229, julio-diciembre 2008, Bogotá.

Ulloa, Astrid (2004), La construcción del nativo ecológico. Instituto Colombiano de Antropologia e Historia-Colciencias, Bogotá.

Vicepresidencia de la República - Observatorio de Derechos Humanos (2005), Dinámica reciente de la confrontación armada en la Sierra Nevada de Santa Marta. Imprenta Nacional, Bogotá.

Recibido: 30.01.2016

Aceptado: 05.04.2016 